The Geneva Papers on Risk and Insurance, 8 (No. 27, April 1983), 147-157

\title{
Public Insurance Provision and Non-Market Failures
}

\author{
by Herman B. Leonard and Richard J. Zeckhauser *
}

\begin{abstract}
It is a common observation of microeconomic theory that there are numerous cases where private insurance markets cannot be expected to function well. This is frequently used as the basis for an argument that public intervention in or provision of insurance can improve on private market outcomes. Though we agree that there are many imperfections of private insurance markets, we argue that this is not at all the same thing as the statement that public provision will be an improvement. There are features that appear to be inherent in public provision of insurance that constitute what we call "non-market failures"; in many cases, these are more severe than the private market failures public provision is alleged to address. In particular, we note that public provision is subject to many of the same incentive problems that lead to private market failure. Moreover, it is subject to a political sociology that often leads, over time, to a diversion of public insurance programs from their original goals, and thus to substantial inefficiency and inequity. We conclude that while there may be cases where public insurance is desirable, there are many others where - less attractive in application than it appears in principle - it will be inferior to even poorly functioning private insurance arrangements.
\end{abstract}

\section{Introduction}

Who shall provide for a citizen's security ? Historically in Western societies, the responsibility has rested principally with the individual and the family. But many risks are difficult for even an extended family to accommodate, and so a private insurance industry has arisen to protect individuals against risks such as the loss of earnings associated with disability or death. Some policy makers have felt, however, that private insurance markets do not provide adequate, fair or sufficiently inexpensive coverage against important risks to individual health, employment, and social well-being. As a result, governments have become increasingly, indeed extensively, involved in the provision of insurance, both through regulation of private insurance and through direct provision of riskbearing services.

* John F. Kennedy School of Government, Harvard University ; article written as a follow-up discussion to the sixth annual lecture of the Geneva Association (this issue). 
In his very thoughtful paper, Raymond Barre ${ }^{1}$ has dissected this development, examined the implications of asking the government to insure individuals' economic status, and derived a set of policy conclusions. His balanced recommendations call for a continued, but more restrained, public role in providing economic security, and ultimately for more cooperation between the public and private sectors in this sphere.

In his accompanying commentary on Barre's essay, Joseph Stiglitz ${ }^{2}$ assesses the microeconomic arguments for public intervention in protecting individuals against risk. This essay provides a cautionary counterbalancing thrust to that critique. There are, to be sure, many situations in which private insurance markets cannot be expected to work well. But often, we argue, public provision will be no better, and quite possibly worse.

Public involvement necessarily brings with it a political sociology that can often lead public insurance programs away from their original goals in inefficient and inequitable directions. Instead of merely trying to correct for private market imperfections, programs may evolve to include a broader redistributive mission and to reflect a wide range of other political considerations. Benefits become entitlements and then rights. An "employment constituency" develops around the program, and will defend it with little regard for the legitimate interest of the originally intended beneficiaries.

In the idealized world of microeconomic theory, where the public sector acts strictly as a market-perfecting agent, its special powers can indeed correct for some important problems that no private agent can address. In some cases, however, the government will be in no better position that private agents to overcome market imperfections. And nearly always, the government's intervention will take place in a less than ideal political context, so we should be careful to allow for the costs of less than ideal implementation.

Many of the problems that make it difficult for the private market to provide insurance efficiently also affect public provision. Moreover, the nature of political debate in open democratic societies prevents public insurance from performing in reality as well as it does in economic theory. These "non-market failures" of public provision can take several forms. First, public provision ordinarily escapes the useful discipline of the private market in balancing the budget of the provider. Second, some features of the information and incentive structure that make it difficult to provide private insurance perfectly are inherent in the nature of the insurance itself, and so apply to public provision as well. Finally, the politics of public provision complicates government insurance programs - a difficulty easily overlooked when public and private provisions are compared in an idealized setting.

\section{The loss of market discipline}

To remain on the market, private insurance products must collectively achieve an overall budget balance that indicates consumers value the services at least as much as they cost to produce. By contrast, government insurance programs frequently charge

1 See page 88 , this issue.

2 See page 105, this issue. 
premiums that bear little relation to the economic reality of the transactions involved. For example, the loan guarantees extended to Chrysler in 1979 by the U.S. Congress amount to a substantial insurance policy whose risks are borne by the taxpayers. The government charged a nominal "premium" for these guarantees - hardly enough to cover the costs of its participation in the negotiations to refinance the company ${ }^{3}$. It made no serious attempt to estimate the expected costs of the taxpayer's contingent liability, and has not systematically assessed the overall balance of transactions under this program. Whether or not the subsidy was a good idea from the standpoint of public policy, it is hard to imagine that its size is utterly immaterial. But its treatment in the budget documents and in other government reports presents it as if it were of no interest whatever.

In private markets, the "budget balance" discipline is enforced for each product as well as for the whole collection. For example, if brick buildings are less subject to fire losses than wooden buildings, then the routine operation of market forces will eventually lead to rate differentials reflecting the difference in expected losses. When insurance is provided publicly, however, there is no mechanism to attune rates to levels of risk. If fire insurance were publicly provided, and if its costs were significant, we might expect to end up with too many wooden structures.

The incentives created by private insurance premiums are another useful form of market discipline. Rates tied to degree of risk encourage individuals to reduce their risk levels ; the use of deductibles or co-insurance rates can reduce frivolous claims or unnecessary use of services. When insurance is provided publicly, there is rarely such financial pressure to structure the contracts efficiently.

Another form in which the loss of market discipline may be costly is that it may encourage us to take on programs whose prospective costs are unknown and which turn out to be larger than naively expected. It is often observed that the government is the only institution that can insure against risks whose magnitude is unknown, since it is the only agent that can collect insurance premiums after the fact. This is often offered in support of government provision of insurance. But the sword has two edges. If we would surely opt for insurance no matter what the cost - as, for example, in the case of community disaster relief - then it may be more efficient to wait until we know how much the damage is before we collect the funds to pay for it. ${ }^{4}$ But waiting until after the fact to assess our liability may cause us to be less vigilant than we should be in deciding whether we want to provide insurance at all, thus encouraging an activity. Under the "wait and see" policy, we may have a tendency to endorse programs that turn out to be much more expensive than we imagined, and to overlook ways of reducing risks instead of spreading them. We are also denied any information we might obtain about how expensive the risks are. For example, in passing the PriceAnderson Act, the U.S. government accepted any liability over $\$ 600$ million for any accident related to nuclear power production. Not only does this shift this liability to

3 Indeed, while the taxpayer still faces a sizable contingent liability under this program, the fund that accounts for the loan guarantee transactions actually shows a small surplus as a result of the "premiums" paid.

4 At a minimum, this can save us the cost of collecting when we are lucky and there is no damage. 
the taxpayer, but it denies us any private market signal about how large this risk is. Most important, utilities with a potentially major cost of nuclear production eliminated - there are not premiums associated with Price-Anderson coverage - were given an inappropriate extra incentive to proceed with nuclear power.

\section{Problems of both private and public insurance}

Insurance presents complex problems of efficient contracting, no matter who provides it. Public provision may exacerbate some of these problems. One contracting problem, known in the economics literature as "moral hazard", is that people may take risks precisely because they are insured. With social insurance against poverty in old age, for example, people may provide less for themselves than they would otherwise ; many believe that federal insurance against floods has increased flood damage by inducing people to live in the flood plain. Private insurers generally try to structure their contracts so as to reduce the incentive to take extra risks. Moral hazard may be a more significant problem for publicly provided insurance because there is less financial incentive for the government to structure its insurance contracts efficiently.

Adverse selection can be an issue in publicly provided insurance as well as private, as long as participation is not mandatory. Such public sector programs as federal crop insurance and mortgage insurance are as much subject to this problem as if they were privately provided.

\section{Special problems of public provision}

State involvement in the provision of economic security sets in motion a dynamic political process. Political institutions exert consistent pressures that result in substantial changes in the focus of the original program. Since virtually all programs seem to go through much the same metamorphosis, we may view the process as an intrinsic feature of public insurance policies. We refer to this evolutionary pattern as the "political sociology" of public efforts to provide economic security.

\subsection{Evolutionary dependency}

Public insurance begins as a simple form of risk bearing among individuals who are situated in roughly equivalent circumstances. Whether because moral hazard increases the number of people subject to risk, or because the existence of a government programs sets expectations that are difficult to reverse, participants gradually came to view their risk-reduction benefits as entitlements and eventually as rights. Ultimately they become dependent on the government program.

In the United States, as well as other western nations, income support programs for farmers, Social Security, and government supported medical care programs provide salient examples. Farm price support programs were developed to deal with supposedly unusual situations where due to unusual circumstances, price fell to disastrously low levels. To protect the farmers, and incidentally to keep them in business so that prices would not rise precipitously in the future, agricultural prices were supported through 
government purchases. Price-support policies have changed over the years, sometimes involving purchases, sometimes land banking, and so on. But one feature is unyielding. The government has become a regular participant in the market, supporting farmer's incomes by reducing the production of agricultural products.

Social Security is an annuity program for older citizens. It started - ostensibly - as a social program to ensure against poverty in old age. It has gradually lost most of its "insurance" features. In recent years in the United States, the economic well being of the elderly has risen dramatically. Today, if one imputes the income from housing and medical programs, the per capita income of the elderly exceeds that of the population at large. The Social Security system, which is funded on a pay-as-you-go basis, is now in precarious financial shape. As a means of restoring the fiscal integrity of the system, some reductions in increases in future benefits have been proposed. But such proposals have met such a storm of criticism that most have quickly been abandoned.

In the past several decades, medical care costs as a percentage of GNP in the United States have roughly doubled. Government entitlement programs have been the major source of this expansion. For example, federal government hospital expenditures rose from $\$ 0.4$ billion in 1964 to $\$ 45$ billion in 1980. (Hospital costs are roughly $45 \%$ of the nation's total health-care bill.) It is widely believed that the marginal benefits that the poor receive from health care programs are small. Yet attempts to trim government-supported medical expenditures get virtually no political support. Indeed in March 1983, a Presidential commission on medical care - the vast majority of whose members were appointed by Ronald Reagan, the most conservative President of the modern era - reaffirmed the nation's obligation to provide such care as a right. Even cost-control measures such as minor copayments of a $\$ 1$ per visit are subjected to severe criticism in public debate, for they "limit access". No doubt a major portion of the support for medical service delivery programs come from the institutions, e.g. hospitals, whose very survival would be threatened with any curtailment of services.

\subsection{Redistributive orientation}

Over time, the relative importance of the redistributive component of public insurance programs generally increases. Agricultural programs that began as an attempt to stabilize farm income are now widely recognized as a systematic means of raising the level of farm incomes by reducing agricultural output. It is by no means obvious that redistribution is best accomplished through programs nominally designed to provide social insurance against risks. And the fact that such programs have evolved their redistributive functions only gradually, under political pressures, makes us wonder whether they truly reflect the choices society would make if it focused directly on the question of redistribution.

\subsection{Employment constituency}

The public provision of riskbearing services tends to generate a strong constituency among people whose employment is directly related to the program. These groups 
become part of political constituency that supports the program and generally resists major alterations (aside from growth). Public health insurance clearly benefited the health professions as well as the poor and the elderly; welfare and unemployment insurance provide a livelihood for social workers and state employees. Private insurance also provides jobs, of course, but private-sector employees seldom have a direct voice in deciding whether to expand, maintain, or cut the programs in which they work. Public sector employees, in contrast, often play powerful political roles.

\subsection{Obfuscation of costs}

In the private sector, there are strong incentives for managers to monitor and control costs, and strong sanctions are applied to those who deliberately misrepresent financial and other performance data. In public sector programs, however, these incentives are at best weaker and may run in the other direction. In any program where risk is a component of cost, costs can be misrepresented simply by underestimating the risk levels involved. Without many recurring events of the type one rarely sees in a policy context, it is difficult to demonstrate that a probability estimate is in error. Given the increasing public concern about the cost of government, there is also at least a potential incentive to move costs off the budget or to reduce estimates of future costs that remain to be borne.

A good example of this phenomenon is public pensions, which are generally substantially underfunded; the taxpayers who insure government workers against law incomes in old age are unaware of the magnitude of the future payments they will be asked to make. Various risk guarantee programs present the same problems. The Overseas Private Investment Corporation (OPIC), for example, is an agency of the U.S. government that insures private investors against the political risks of property expropriation in foreign countries. A nominal insurance premium is charged for this service. No one has systematically estimated the value of the contingent liabilities the government has assumed, but OPIC's reserves are less than 10 percent of the value of the investments it has guaranteed. It thus represents a sizable potential liability of taxpayers ; these "costs" are not discussed and appear to play only a small role in policy deliberations about the guarantee policies of the agency.

\subsection{Social myopia}

Public provision of insurance, like other public programs, sometimes involves a conspicuous myopia. Though the public sector is often described in theory as acting in the interests of all future generations, the tenure of most political officials is relatively short. Thus, programs that have current benefits but deferred costs may be particularly attractive politically even though they may not be in the best interests of taxpayers generally. Many insurance programs appear to have this character. For example, the social security system and most public pension systems are explicitly designed to pay benefits in excess of their visible costs in the early years. Particularly when the size of the hazard insured against is uncertain, it may be easy to underfund social insurance funds. Government guaranteed mortgages were used in the 1960s and 1970s to advance social goals in decaying urban areas; though the program was nominally self-funding through insurance premiums, it turned out after the fact that the premiums for many 
of the loans had been far too low. The powerful political pressures of meeting the perceived needs of the community without increasing the tax burden may push politicians toward programs whose costs can be deferred ; many social insurance programs fall into this category.

\subsection{Cumulative distortions}

Although public insurance programs are usually initiated in response to an immediate, short-term problem, most eventually become long-run policies. Moreover, while the inefficiency generated by each program may seem small in itself, the cumulative, interactive effect can be substantial. One reason why Congress provided the Chrysler loan guarantees, for example, was that the failure of the company would have led quickly to the financial failure of its pension fund. Under the terms of the 1974 Employee Retirement Income Security Act, Chrysler employees' pensions were guaranteed by the Pension Benefits Guarantee Corporation, an agency of the government. Thus, the public provision of insurance against the risk of pension failure in 1974 contributed to the decision in 1979 to provide public guarantees of debt to investors in a (formerly) private company. Moreover, some would argue that the government has moved consciously in other policy areas, such as the awarding of defense contracts, to insure the success of the new Chrysler; this would represent another (difficult to estimate) set of costs attendant to a policy that may still be cumulating.

The cumulative distortion may also run in the other direction : the existence of one social program may make it more attractive to have another social insurance program. For example, the strong commitment of the government to community disaster relief may make it seem more attractive to have a federal flood insurance program that can (partially) offset the costs. Once a program is in place to guarantee minimum incomes for the elderly, a broader social security program that ostensibly prevents poverty among the elderly may appear more attractive. Thus, social programs, and in particular social insurance programs, may build upon one another.

\subsection{Political targeting}

Social riskbearing programs are generally developed to aid groups defined by their exposure to a particular hazard. Over time, however, the size of the group exposed to the hazard may increase, precisely because once insurance is available, the personal, though not societal costs of exposures have decreased. Moreover, an employment constituency develops. Because public sector programs are inevitably dependent on their ability to command political resources, benefits tend to be focused on those who can generate political support, and not necessarily those exposed to the worst hazards. Similarly, the redistributive function acquired by most programs over time, is usually contrary to the original intent of the program. Moreover, it is rarely directed toward those whose need is objectively greatest. For example, some trade protectionism might be viewed as a social program to shift the risks of technological change from workers in particular industries to taxpayers. But the industries that have been particularly successful in getting government trade assistance are not ones with particularly poorly paid workers. U.S. steel and automobile workers earn more than the great majority of 
the working class. Benefits from these programs tend to concentrate on the most politically powerful groups, not the most economically disadvantaged.

\subsection{Inducement to regulation}

Once the government enacts some form of risk protection program, it will encourage behavior that generates the outcomes that will qualify for transfers, Individuals will be poor more often, unemployed more often, will go to the hospital more often, and so on. Companies will layoff individuals who will qualify for government provided unemployment insurance with greater frequency, will reduce the funding of their insured pension programs, make less effort to assure the safety of their nuclear plants given that the government pays for losses beyond certain limits. These problems are all generated by moral hazard, and they are commonly recognized as problems of public insurance programs. When the government tries to fix them, it frequently produces poor results in other areas.

In an effort to contain costs, governments will take further interventionist steps to control behavior. Individuals on welfare are subjected to a man-in-the-house rule. Those who are unemployed must report to the unemployment office regularly and demonstrate good faith efforts to secure a job. Companies whose pensions are protected, as is now mandatory in the U.S., under the Pension Benefit Guarantee Corporation, must meet certain funding standards. And nuclear plants must meet federal safety inspections.

Such government regulatory efforts may suffer severe problems. A central difficulty is that it may be difficult to determine what conditions prevail. For example, at Three Mile Island, human error as opposed to some more readily inspectible physical problem, was the primary source of the accident. The problem of determining who is eligible to work, and requiring them to do so when able, encounters civil liberty problems, beyond its considerable informational requirements.

A second major difficulty arises because regulation tends to encourage or require a uniform response. For example, once the Pension Benefit Guarantee Corporation was put into effect, it was no longer desirable for companies to provide funding beyond the minimal amount. Thus, it was not surprising, for example, when a number of companies with pension plans funded above the required minimum chose to dramatically reduce their funding. No less surprising, though perhaps more consequential, many companies with underfunded plans chose to terminate them. Here we observe a critical problem with government regulatory efforts designed to control costs of protective programs. Ideally, the government would encourage actors to engage in " risk reducing" behavior, and would reward them through a reduction in some price by doing so. But the whole nature of government involvement militates against pricing at all, much less pricing by risk level. Hence, we tend to see uniform standards ; floor levels of safety becomes ceilings as well. Once the government provided loan guarantees to Chrysler it became, in effect, a major creditor of that company. The Treasury attempts to monitor and direct Chrysler's performance. Once rent control for housing is put in place, assuming that the rent constraint is binding, landlords lose the incentive to maintain standards. Government housing codes and inspection become necessary. And once there is rent control on energy prices, fuel efficiency standards and even 
temperature control standards are required to prevent the excessive purchase of an underpriced resource. A major consequence of government protective efforts is to touch off a process of pyramiding intervention as a means of dealing with the cost control problems created by the first intervention. One of the major arguments for government discouragement of smoking behavior is the financial consequences of health impairment that through insurance that is imposed on the population as a whole. If the U.S. were to enact a program of national health insurance, public pressures to reduce smoking might be substantially increased.

\subsection{Extraneous programs}

Social insurance is commonly alleged as a justification for public programs in which the insurance component is small or nonexistent. The U.S. Social Security system, for example, was designed from the start to be a transfer program from the current work force to the elderly ; it was presented as "insurance" to make it palatable both to recipients and to the public that was asked to underwrite it. Similarly, as noted earlier, farm income "stabilization" programs are actually subsidies. Such programs may be worthwhile in themselves, but depicting them as insurance confuses the issue.

Just as market failures prevent private insurance provision from functioning perfectly, public provision is subject to distinctive kinds of problems which we have termed non-market failures. These intrinsic difficulties in public provision must be considered before one can be confident that government insurance programs will be more efficient than the admittedly flawed reality of private provision.

\section{Joint public and private insurance}

The conviction is growing in many areas of public policy that combinations of public and private action may be the best prescription for many of society's ills. Indeed, Raymond Barre reminds us of the need for more effective coordination of public and private efforts in providing protection against risk, and outlines some means for achieving superior coordination. Without doubting the general truth of this principle, we believe that joint public and private provision of insurance should be approached with caution.

\subsection{Co-optation of the players}

When the public sector provides insurance - that is, pays the bills - but the private sector provides the insured services, the private agents are generally co-opted in the process. While the medical profession originally opposed the development of Medicare, it subsequently accommodated itself to this program, and now profits handsomely from it. The airline industry initially fought regulation, which was offered as a means of "stabilizing" service levels and avoiding wasteful competition. But it later adjusted to operating in an extensively regulated environment, and strenuously opposed deregulation efforts. 
The programs most likely to be implemented are precisely those in which the employment and other benefit constituencies are best able politically to control the program's implementation so that it turns out to be in their interest. The medical profession, for example, could stall the introduction of Medicare until it became clear that the program would not cramp physician's styles in their practices.

\subsection{Forcing redistribution on the public sector}

When public and private insurance systems overlap or interact, the public sector seems likely to lose in the bargain. For example, public health insurance includes deductibles to reduce moral hazard costs, but because private companies are allowed to offer insurance for the deductibles, moral hazard is reintroduced into the public program. The costs are borne by the public, and the private insurers make a profit. Similarly, when the public agrees to provide insurance for those rejected from private markets, as in the case of Small Business Administration loan guarantee programs, the "cream-skimming" by the private market is clearly costly to the public.

\section{Conclusion}

Economists have long dwelt upon the theoretical reasons why private insurance markets may not function well in some circumstances in which idealized state agencies could act as market-perfecting agents. Much less attention has been devoted to identifying the systematic "non-market failures" that public provision is likely to engender. Our view of the political sociology of public programs generally, and of public insurance programs in particular, is that non-market failures are as intrinsic to public activities as market failures are to private activities.

Our major argument is that when the state becomes involved in the provision of economic security, an evolutionary process is set in motion. The end result of this process is a pattern of dependency and redistribution. The original purpose of protecting individuals confronting a common risk through a form of insurance gets lost. Once the dependency situation has been created, matters may deteriorate further. The transfer process may create entitlements, and those entitlements may evolve into rights.

There are three classes of objections to the situation that results : (1) The ultimate outcome may be one that was neither foreseen nor desired at the time the policies promoting it were enacted. (2) The resulting situation is inefficient in the sense that alternative policies could have led to an outcome that was superior for all. (A principal reason is that potential recipients change their normal behavior, usually by reducing their income, to achieve eligibility for transfers.) (3) Many of the beneficiaries of these protection programs are not worse off than the average citizen. A second privileged class of beneficiaries includes those who administer the program or deliver its services.

When should the public be involved in the provision of insurance ? When (1) there are severe failures of private markets and (2) the inefficiencies associated with the political context of public provision can be limited. These conditions may be met in a variety of areas. For example, no private actor will take sufficient interest in the 
maintenance of a stable and healthy macroeconomy - here clearly the public sector must play a risk-bearing and risk-reducing role. This need not call for active intervention, but some policy is surely required. Similarly, guaranteeing the value of money and the stability of the banking industry are natural function for the public sector, since it will usually have much greater credibility than private institutions in backing fundamental economic units. But, we suggest, a careful review of many public programs with ostensible insurance purposes would reveal that they were not playing a predominant role in spreading risks efficiently, and that there should be a policy leaning against their continuance and a strong predisposition against their expansion.

Our central point has broader implications for the general problem of public versus private provision of services. It is inherently unfair to compare the reality of an admittedly, and thoroughly studied, imperfect private market reality with an idealized public sector agency. (The symmetric error is no less objectionable.) Objectivity, fairness and good policy requires a comparison of one imperfect reality with another. 